Supporting Information for:

\title{
Large cation engineering in two-dimensional silver-bismuth bromide double perovskites
}

Fabian Schmitz, Jonas Horn, Nicola Dengo, Alexander E. Sedykh, Jonathan Becker, Elena Maiworm, Péter Bélteky, Ákos Kukovecz, Silvia Gross, Francesco Lamberti, Klaus MüllerBuschbaum, Derck Schlettwein, Daniele Meggiolaro, Marcello Righetto, Teresa Gatti

\section{Table of Contents}

- Optical microscope images of monolayer 2D (RA) ${ }_{4} \mathrm{AgBiBr}_{8}$ compounds (Figure $\mathrm{S} 1$ )

- High wavenumbers region of the Raman spectra of the four (RA) ${ }_{4} \mathrm{AgBiBr}_{8}$ compounds (Figure S2)

- Modelling of main vibrational modes in $3 \mathrm{D}$ bulk $\mathrm{Cs}_{2} \mathrm{AgBiBr}_{6}$ and in a single layer of $\mathrm{Cs}_{2} \mathrm{AgBiBr}_{6}$ (Figure S3)

- Crystal data and structure refinement for (PEA) ${ }_{4} \mathrm{AgBiBr}_{8}(\mathrm{Table} \mathrm{S} 1)$

- Details of the single crystal structure of (PEA) ${ }_{4} \mathrm{AgBiBr}_{8}$ (Figures S4, S5, S6)

- Thermogravimetric analysis of the four (RA) ${ }_{4} \mathrm{AgBiBr}_{8}$ compounds (Figure S7)

- Representative HR-TEM images of the four (RA) ${ }_{4} \mathrm{AgBiBr}_{8}$ compounds with details on repetitive structures and associated distance (Figure S8-S11)

- $\quad$ SAED patterns of the four (RA) ${ }_{4} \mathrm{AgBiBr}_{8}$ compounds (Figure S12)

- $\quad$ TEM EDX analysis of the hydrothermally synthesized (BA) ${ }_{4} \mathrm{AgBiBr}_{8}$ crystalline sample (Figure S13)

- Thin film XRD patterns of spin-coated thin films of the four (RA) ${ }_{4} \mathrm{AgBiBr}_{8} 2 \mathrm{D}$ monolayers double perovskites (Figure S14)

- Photos of the thin films obtained from the four (RA) ${ }_{4} \mathrm{AgBiBr}_{8} 2 \mathrm{D}$ monolayers double perovskites (Figure S15)

- Cross-section SEM images of spin-coated thin films of the four $(\mathrm{RA})_{4} \mathrm{AgBiBr}_{8} 2 \mathrm{D}$ monolayers double perovskites (Figure S16)

- $\quad$ AFM topography images of spin coated thin films of (BA) ${ }_{4} \mathrm{AgBiBr}_{8}$ and $(\mathrm{PEA})_{4} \mathrm{AgBiBr}_{8}$ (Figure S17)

- DLS spectra of the solutions used for processing the four ( $\mathrm{RA})_{4} \mathrm{AgBiBr}_{8} 2 \mathrm{D}$ monolayers double perovskites into thin films (Figure S18) 
- AFM topography scans of spin-coated thin films of (iBA) $)_{4} \mathrm{AgBiBr}_{8}$ and (HA) $)_{4} \mathrm{AgBiBr}_{8} 2 \mathrm{D}$ monolayers double perovskites 2D monolayers double perovskites (Figure S19)

- WF of (RA) $)_{4} \mathrm{AgBiBr}_{8}$ as a function of the calculated dipole moment of the organic cations $\mathrm{RA}^{+}$(Figure S20)

- Diffuse reflectance spectra of the four hydrothermally synthesized (RA) ${ }_{4} \mathrm{AgBiBr}_{8} 2 \mathrm{D}$ monolayer double perovskites crystalline powders (Figure S21)

- PL spectra of the four hydrothermally synthesized (RA) ${ }_{4} \mathrm{AgBiBr}_{8} 2 \mathrm{D}$ monolayer double perovskite thin films (Figure S22)

- PL spectra of the $(\mathrm{iBA})_{4} \mathrm{AgBiBr}_{8}$ and $(\mathrm{BA})_{4} \mathrm{AgBiBr}_{8}$ hydrothermally synthesized $2 \mathrm{D}$ monolayer double perovskites crystalline powders (Figure S23)

- Integrated PL values for the (RA) ${ }_{4} \mathrm{AgBiBr}_{8}$ series under $3.29 \mathrm{eV}$ excitation (Table S2)

- $\mathrm{G}_{0} \mathrm{~W}_{0}$ band gap convergence of $(\mathrm{BA})_{4} \mathrm{AgBiBr}_{8}$ vs computational setup (Table S3)

- $(\mathrm{BA})_{4} \mathrm{AgBiBr}{ }_{8} \mathrm{BSE}$ spectrum convergence vs number of k-points in BZ (Figure S24) 

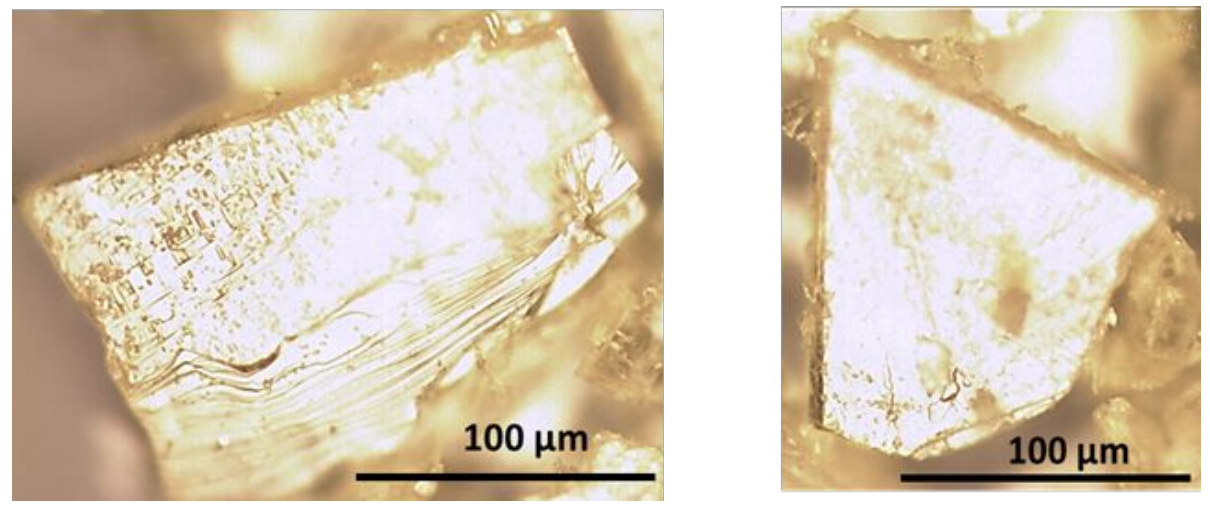

Figure S1. Optical microscope images of a prototypical crystal of $2 \mathrm{D}(\mathrm{RA})_{4} \mathrm{AgBiBr}{ }_{8}$ compound that evidence the platelet-like structure and crystal growth along the (001) plane.

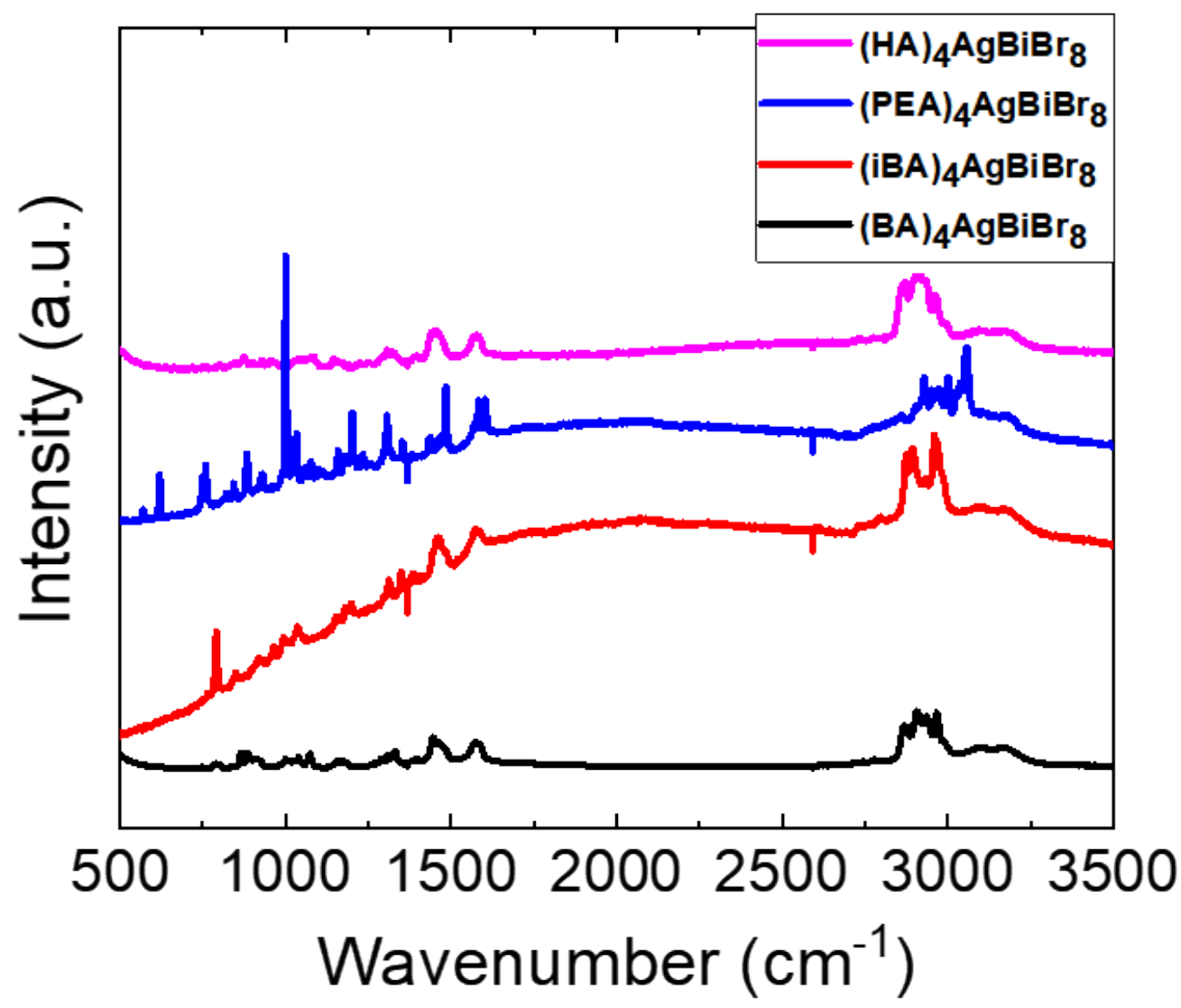

Figure S2. High wavenumbers region of the Raman spectra of the four (RA) ${ }_{4} \mathrm{AgBiBr} 8$ compounds. 


\section{a) 3D periodic}

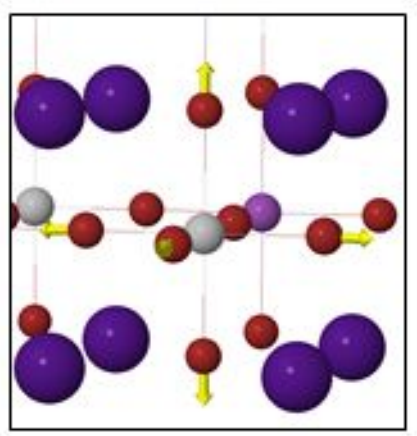

$A_{1 g} 181 \mathrm{~cm}^{-1}$ b)

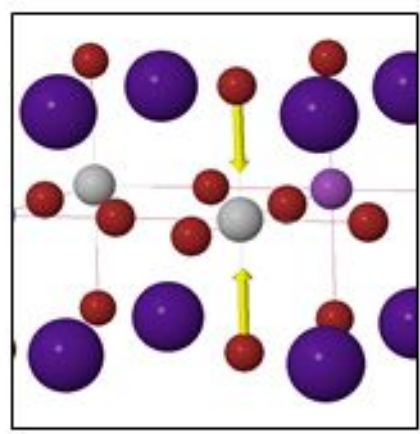

$A_{1} 87 \mathrm{~cm}^{-1}$
2D periodic

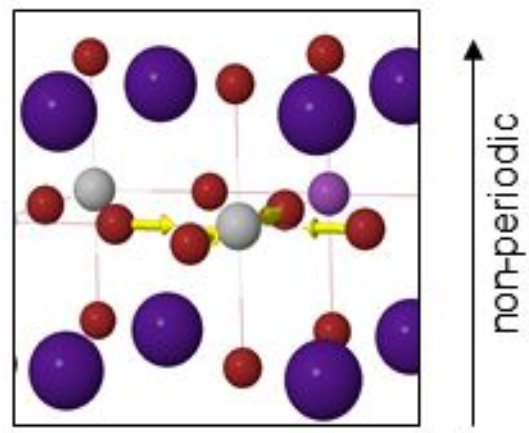

$A_{1} 177 \mathrm{~cm}^{-1}$

Figure S3. Vibrational modes and relative frequencies associated to symmetric stretching of the $\mathrm{Ag}-\mathrm{Br}$ octahedra in a) 3D bulk $\mathrm{Cs}_{2} \mathrm{AgBiBr}_{6}$ and b) in a single layer of $\mathrm{Cs}_{2} \mathrm{AgBiBr}_{6}$ where the periodicity is interrupted in the direction perpendicular to the inorganic layer. By interrupting the periodicity in one direction a decoupling of the stretching mode to $\mathrm{Br}$ displacements perpendicular and parallel to the plane is observed. The stretching modes perpendicular to the plane occur at lower frequencies $\left(87 \mathrm{~cm}^{-1}\right)$ than in-plane stretching $\left(177 \mathrm{~cm}^{-1}\right)$. Based on this model, a softening of the Raman active modes involving metal-Br stretching is expected moving from $3 \mathrm{D}$ bulk to $2 \mathrm{D}$ double perovskites. Vibrational modes have been calculated at the PBE level by selectively displacing six $\mathrm{Br}$ ions in the $\mathrm{Ag}-\mathrm{Br}$ octahedra. 
Table S1. Crystal data and structure refinement for $(\mathrm{PEA})_{4} \mathrm{AgBiBr}_{8}$

\begin{tabular}{|c|c|c|}
\hline CCDC No & \multicolumn{2}{|l|}{2031528} \\
\hline Empirical formula & \multicolumn{2}{|c|}{$\mathrm{C}_{32} \mathrm{H}_{48} \mathrm{Ag} \mathrm{Bi} \mathrm{Br} 8 \mathrm{~N}_{4}$} \\
\hline Formula weight & \multicolumn{2}{|l|}{1444.87} \\
\hline Temperature & \multicolumn{2}{|l|}{$100(2) \mathrm{K}$} \\
\hline Wavelength & \multicolumn{2}{|l|}{$0.71073 \AA$} \\
\hline Crystal system & \multicolumn{2}{|l|}{ Triclinic } \\
\hline Space group & \multicolumn{2}{|l|}{$P \overline{1}$} \\
\hline \multirow[t]{3}{*}{ Unit cell dimensions } & $a=11.4661(5) \AA$ & $\alpha=106.6140(16)^{\circ}$. \\
\hline & $\mathrm{b}=11.5138(5) \AA$ & $\beta=99.6956(16)^{\circ}$ \\
\hline & $\mathrm{c}=17.0237(8) \AA$ & $\gamma=90.0802(16)^{\circ}$. \\
\hline Volume & \multicolumn{2}{|l|}{$2119.93(17) \AA^{3}$} \\
\hline Z & \multicolumn{2}{|l|}{2} \\
\hline Density (calculated) & \multicolumn{2}{|l|}{$2.264 \mathrm{Mg} / \mathrm{m}^{3}$} \\
\hline Absorption coefficient & \multicolumn{2}{|l|}{$12.174 \mathrm{~mm}^{-1}$} \\
\hline$F(000)$ & \multicolumn{2}{|l|}{1356} \\
\hline Crystal size & \multicolumn{2}{|c|}{$0.136 \times 0.135 \times 0.044 \mathrm{~mm}^{3}$} \\
\hline Theta range for data collection & \multicolumn{2}{|l|}{1.804 to $28.281^{\circ}$. } \\
\hline Index ranges & \multicolumn{2}{|c|}{$-15 \leq \mathrm{h} \leq 15,-15 \leq \mathrm{k} \leq 15,-22 \leq 1 \leq 22$} \\
\hline Reflections collected & \multicolumn{2}{|l|}{86176} \\
\hline Independent reflections & \multicolumn{2}{|c|}{$10539[\mathrm{R}(\mathrm{int})=0.0639]$} \\
\hline Completeness to theta $=25.242^{\circ}$ & \multicolumn{2}{|c|}{$100.0 \%$} \\
\hline Absorption correction & \multicolumn{2}{|c|}{ Semi-empirical from equivalents } \\
\hline Refinement method & \multicolumn{2}{|c|}{ Full-matrix least-squares on $F^{2}$} \\
\hline Data / restraints / parameters & \multicolumn{2}{|l|}{$10539 / 1412 / 560$} \\
\hline Goodness-of-fit on $F^{2}$ & \multicolumn{2}{|l|}{1.122} \\
\hline Final $R$ indices $[I>2 \sigma(I)]$ & \multicolumn{2}{|c|}{$\mathrm{R} 1=0.0548, \mathrm{wR} 2=0.1013$} \\
\hline $\mathrm{R}$ indices (all data) & \multicolumn{2}{|c|}{$\mathrm{R} 1=0.0745, \mathrm{wR} 2=0.1080$} \\
\hline Largest diff. peak and hole & \multicolumn{2}{|c|}{2.321 and -3.255 e..$\AA^{-3}$} \\
\hline
\end{tabular}




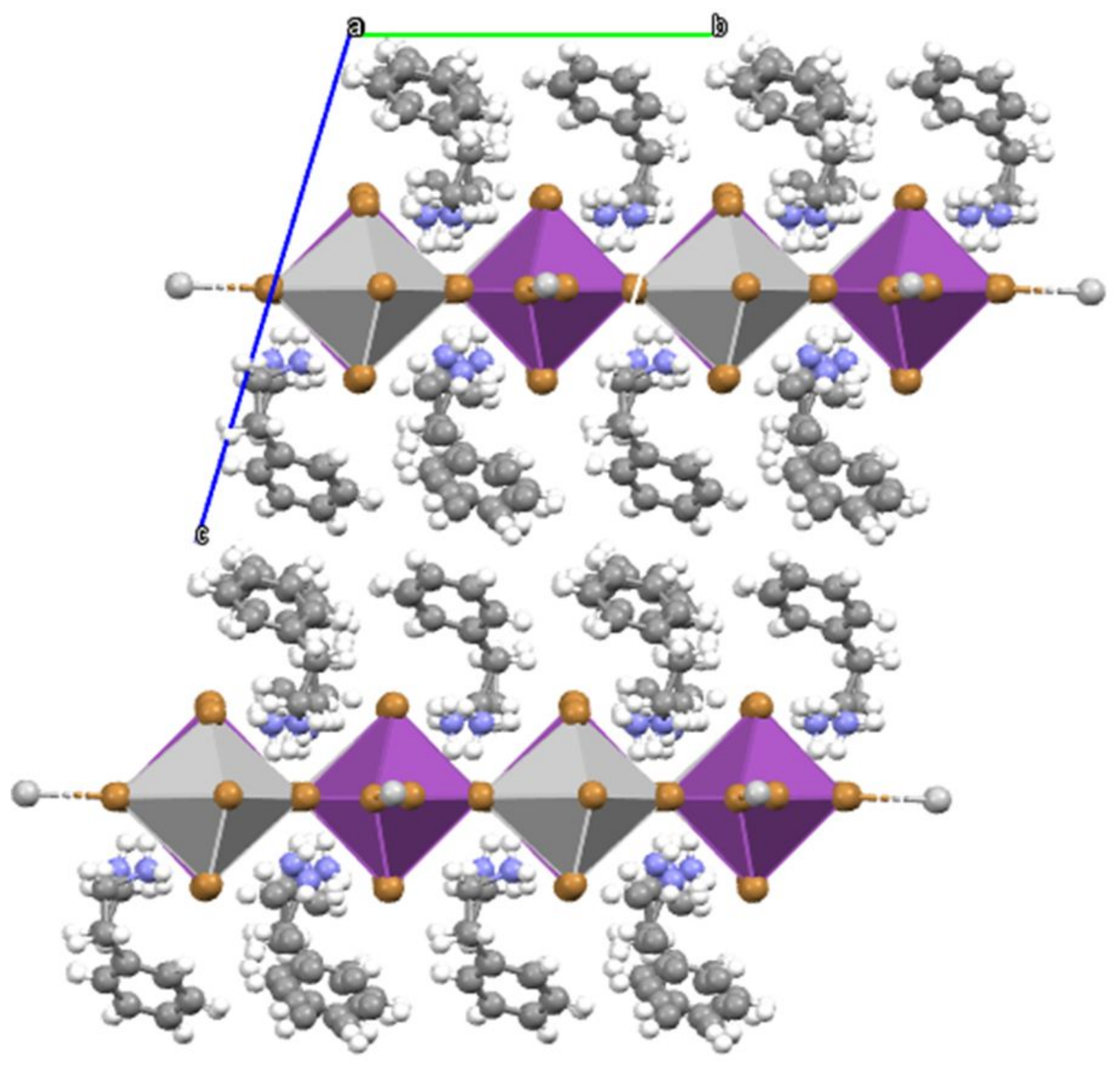

Figure S4. Details of the single crystal structure of $(\mathrm{PEA})_{4} \mathrm{AgBiBr}_{8}$ : view along the a-axis. 


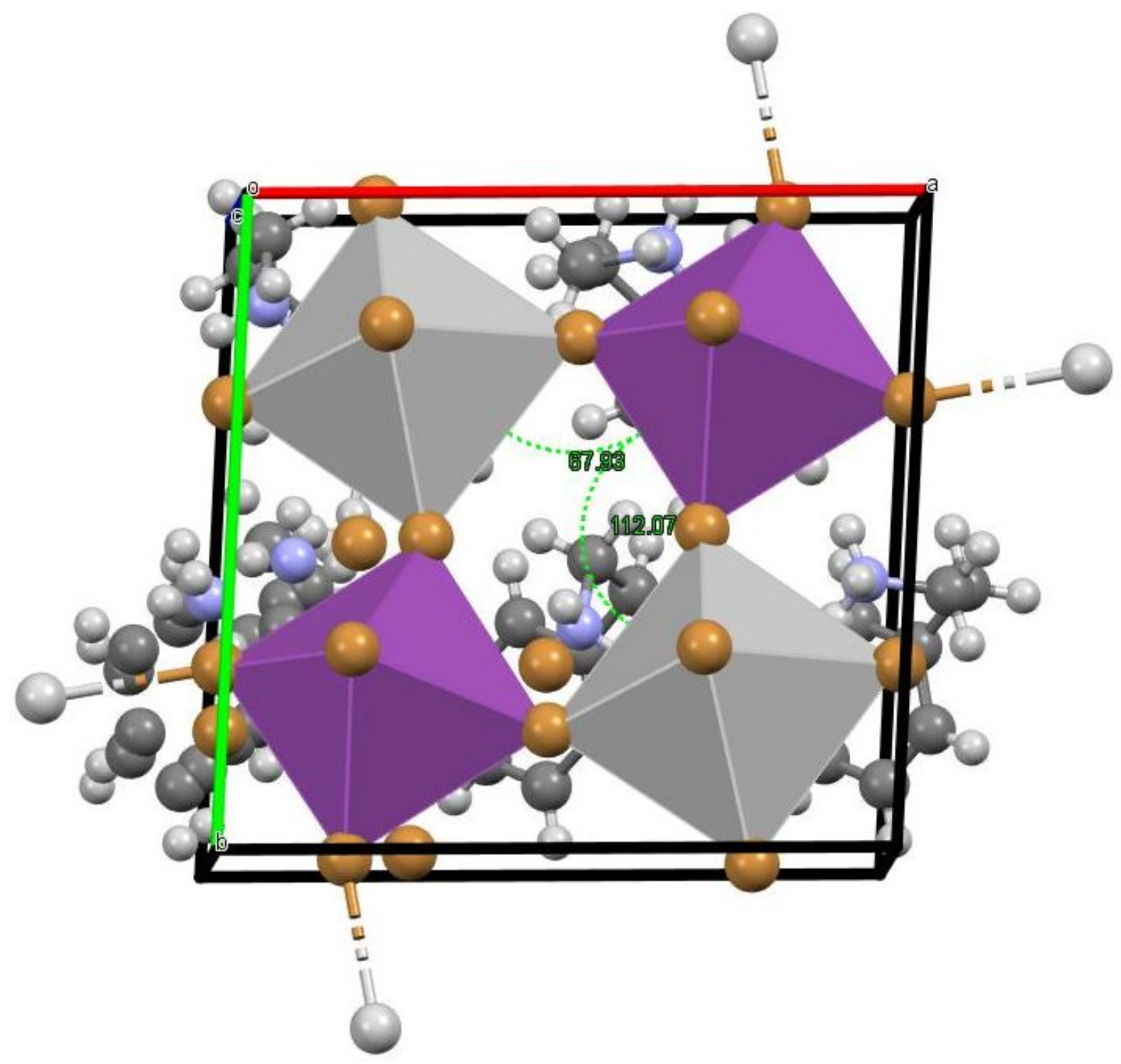

Figure S5. Details of the single crystal structure of $(\mathrm{PEA})_{4} \mathrm{AgBiBr}_{8}$ : view along the c-axis with indications of the value of dihedral angles between two adjacent $\mathrm{Ag}-\mathrm{Br}_{6}$ and $\mathrm{Bi}-\mathrm{Br}_{6}$ octahedra. 


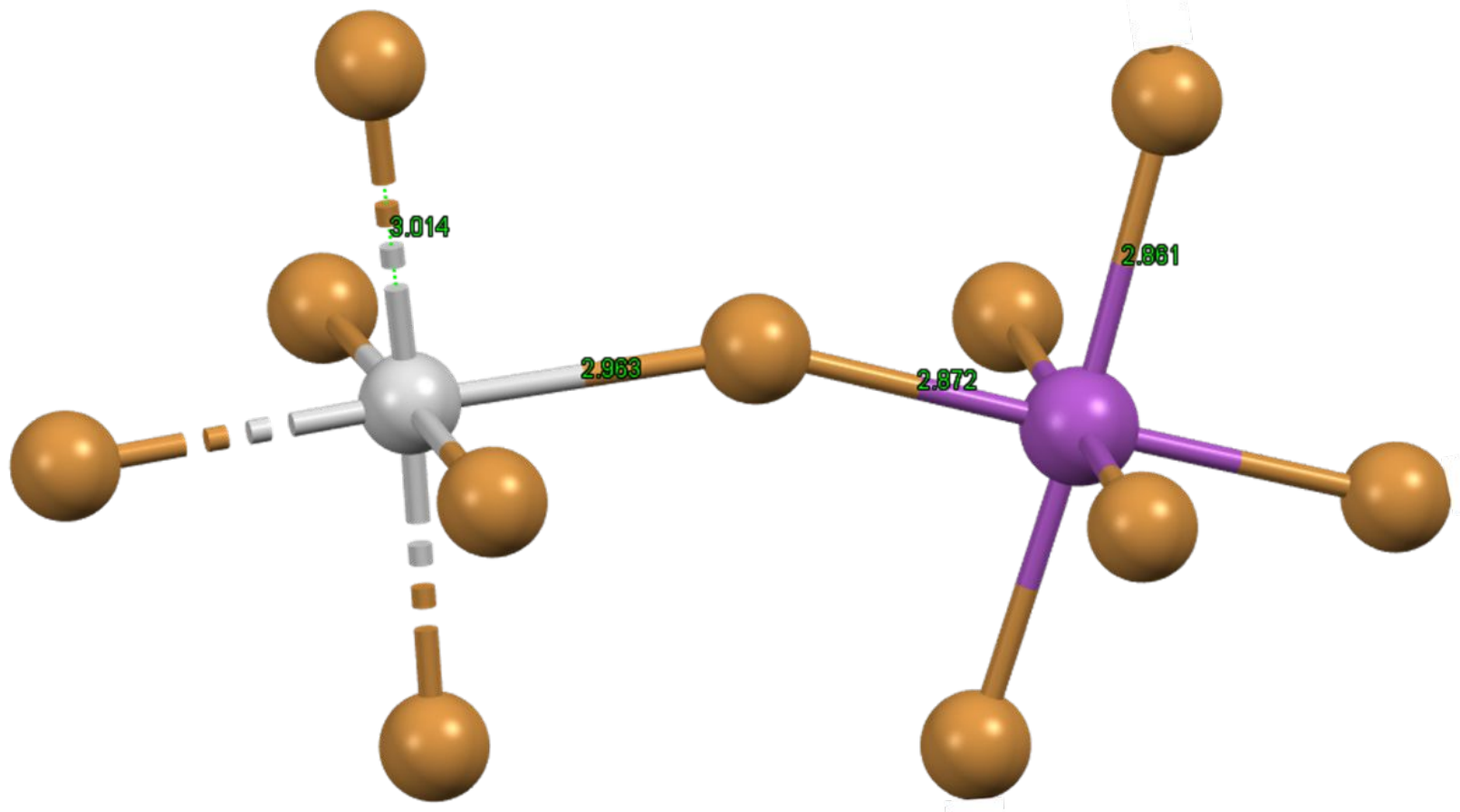

Figure S6. Details of the single crystal structure of $(\mathrm{PEA})_{4} \mathrm{AgBiBr}$ : two adjacent $\mathrm{Ag}-\mathrm{Br}_{6}$ and $\mathrm{Bi}$ $\mathrm{Br}_{6}$ octahedra with indicated the relative bond distances. 

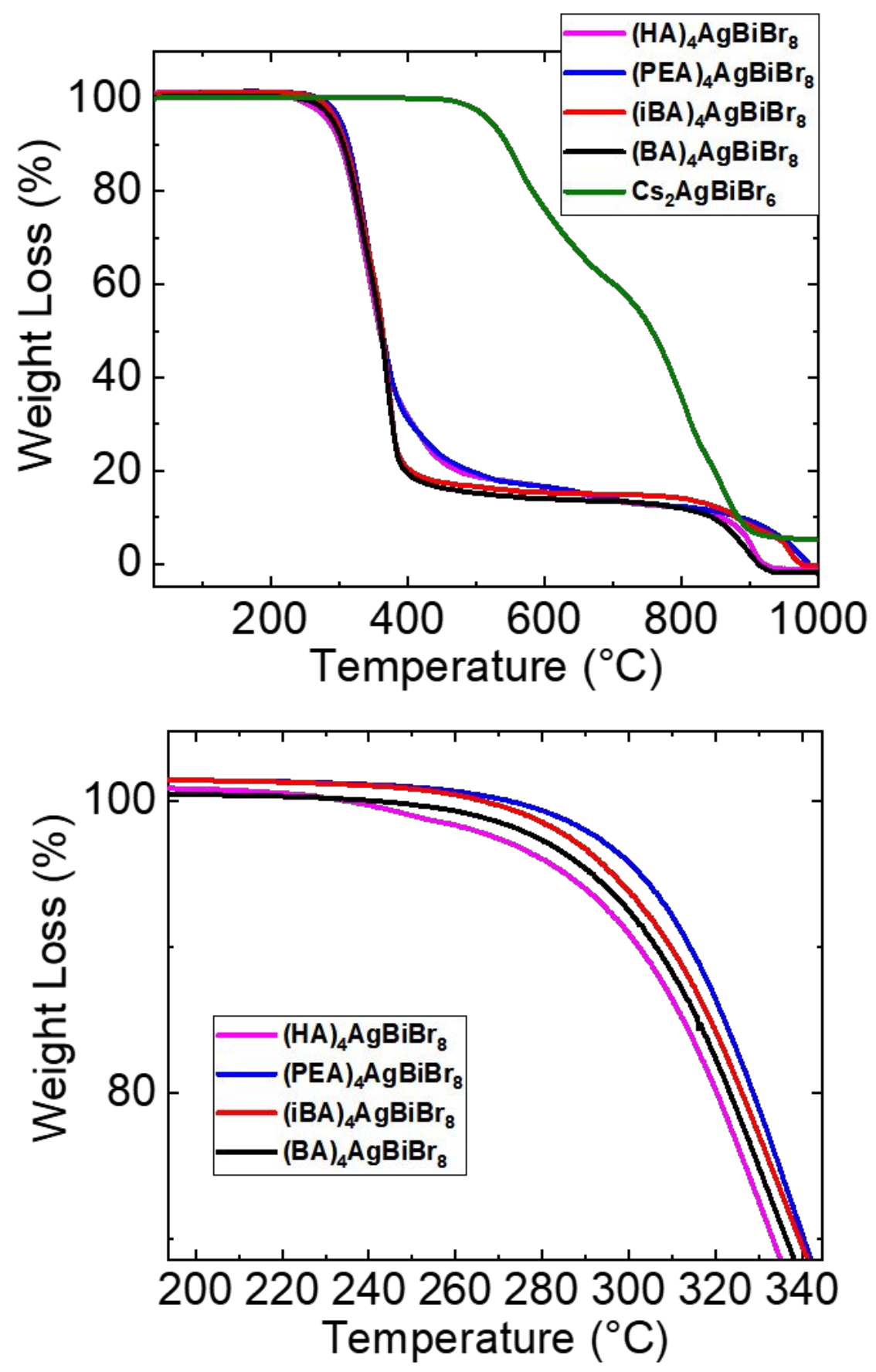

Figure S7. Thermograms of the four $(\mathrm{XA})_{4} \mathrm{AgBiBr}_{8}$ compounds and of the of the reference 3D double perovskite $\mathrm{Cs}_{2} \mathrm{AgBiBr}_{6}$ (top graphs), with detail on decomposition onsets (bottom graphs). 

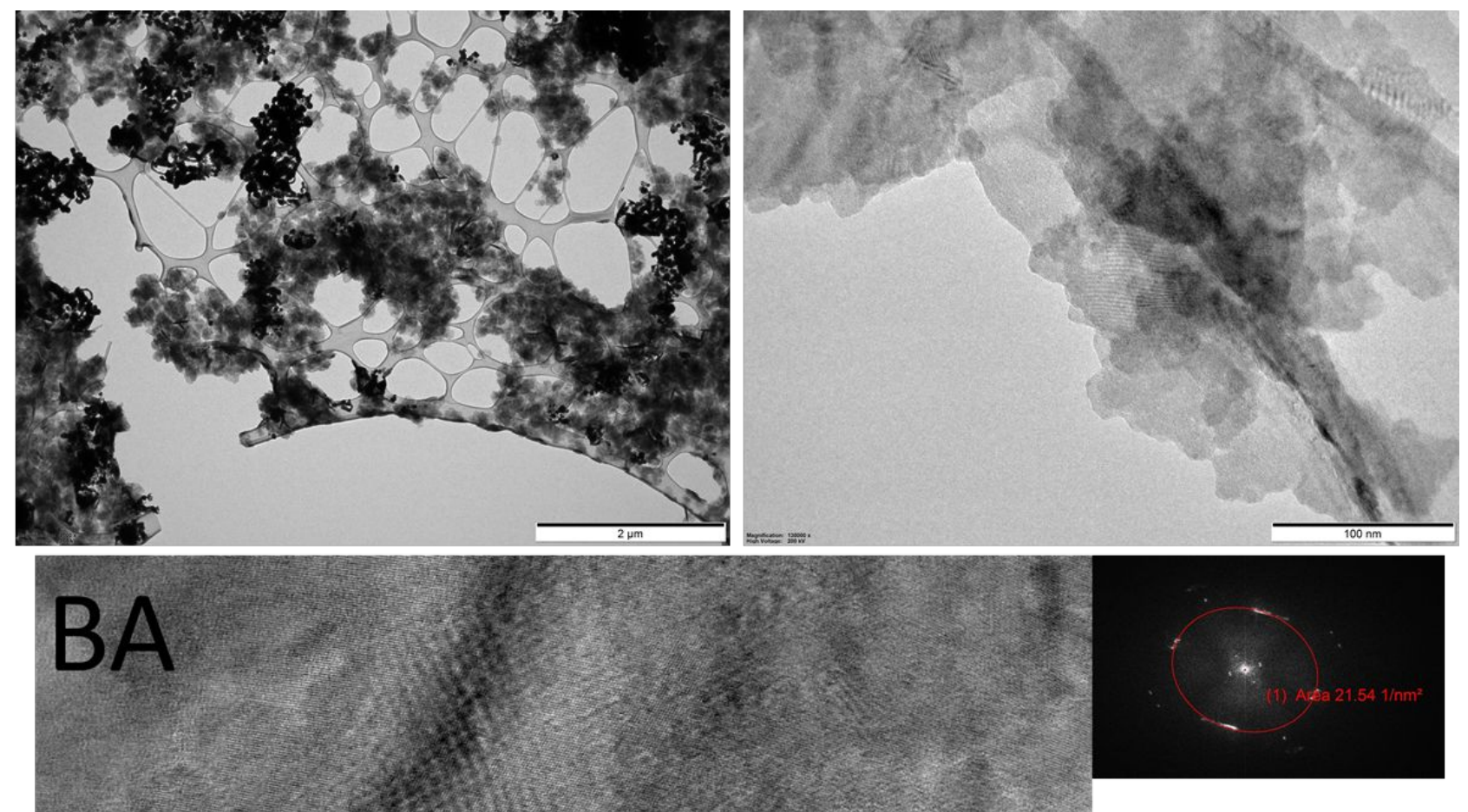

From FFT:

$d=3.82 \AA$

From Image:

$d=3.80 \AA$

Figure S8. Representative HR-TEM images of hydrothermally synthesized (BA) ${ }_{4} \mathrm{AgBiBr}_{8}$ with details on repetitive structures and associated distance (calculated both manually and through FFT). 

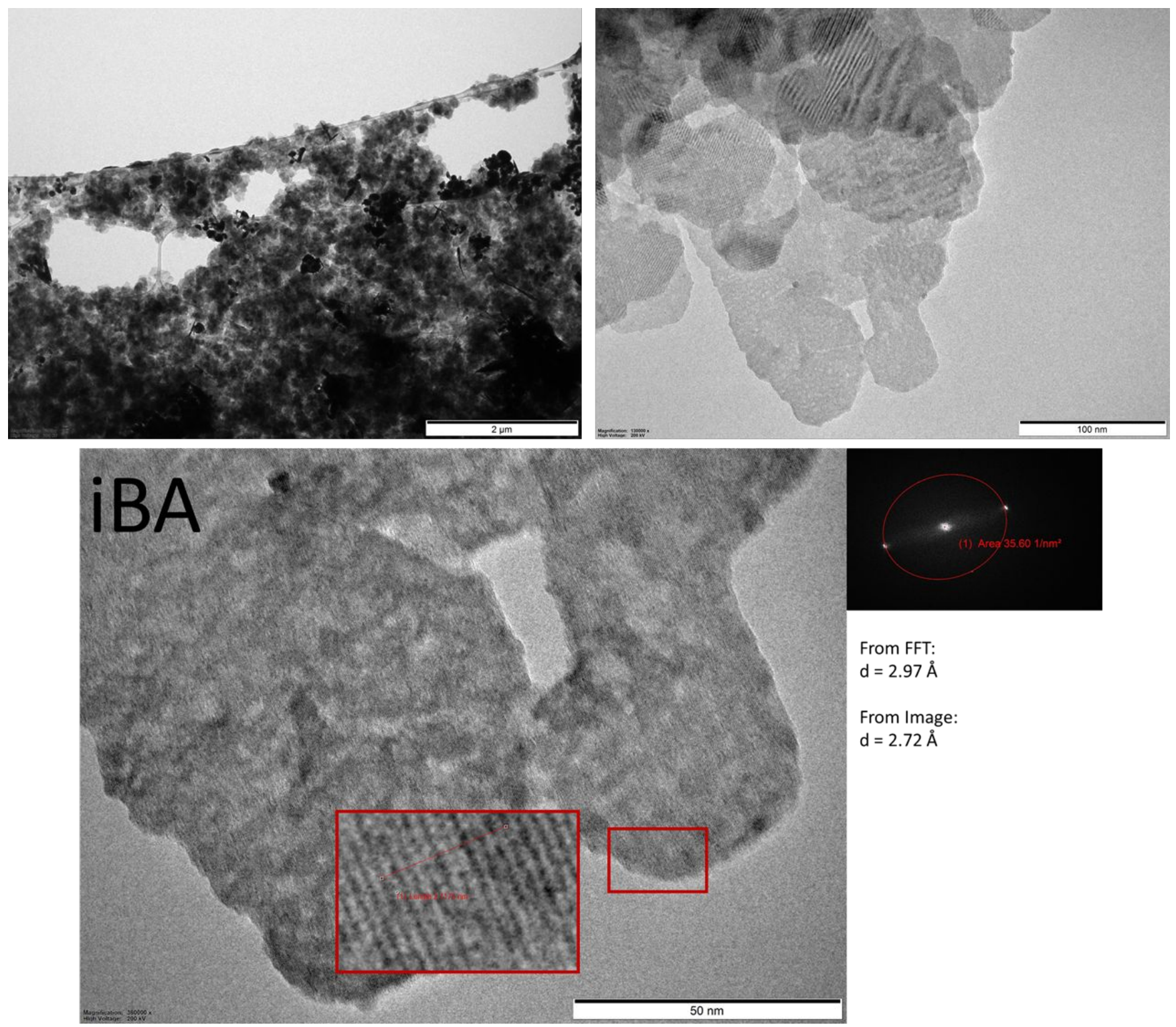

From FFT:

$d=2.97 \AA$

From Image:

$d=2.72 \AA$

Figure S9. Representative HR-TEM images of hydrothermally synthesized (iBA) ${ }_{4} \mathrm{AgBiBr}_{8}$ with details on repetitive structures and associated distance (calculated both manually and through FFT). 

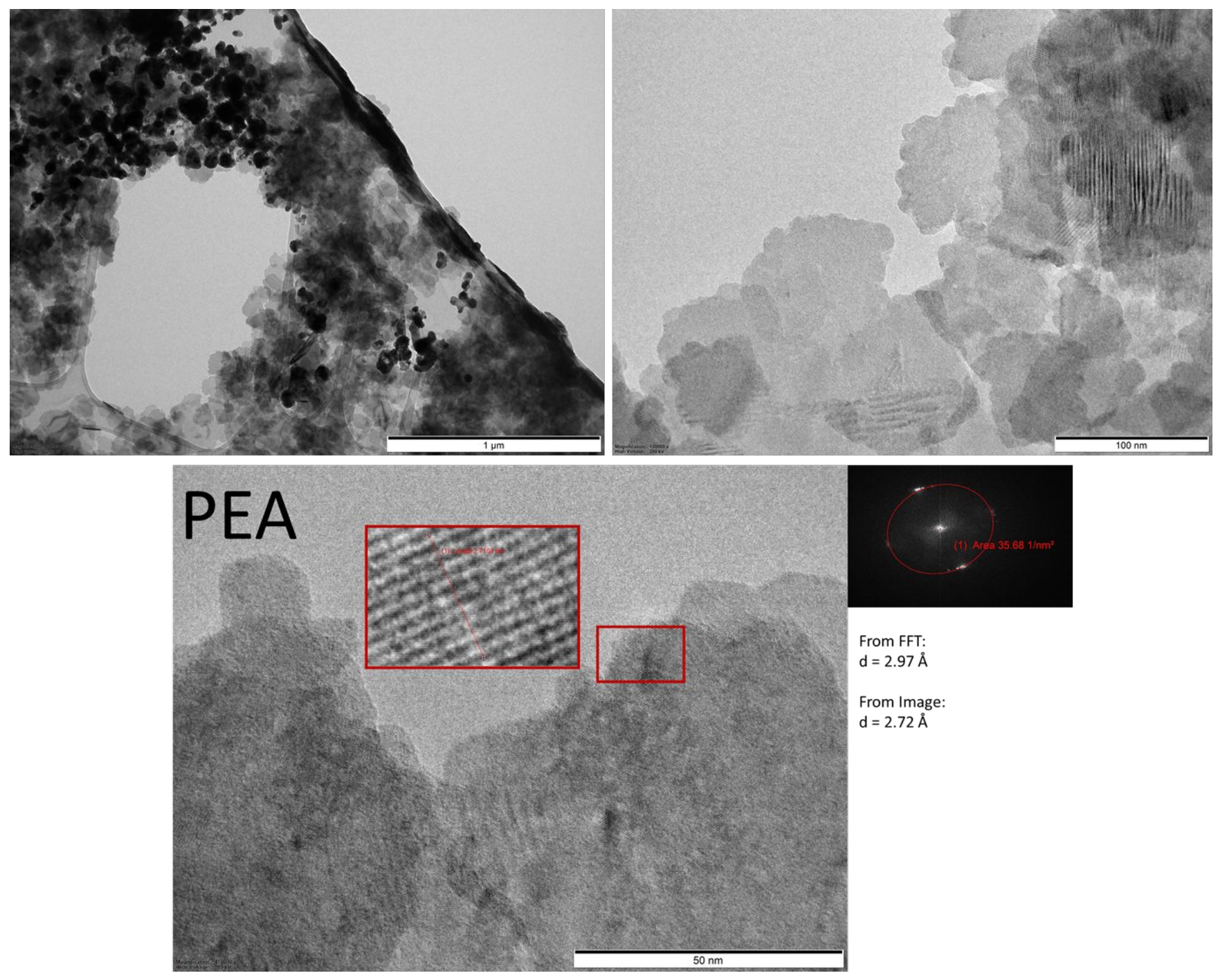

Figure S10. Representative HR-TEM images of hydrothermally synthesized (PEA) ${ }_{4} \mathrm{AgBiBr}_{8}$ with details on repetitive structures and associated distance (calculated both manually and through FFT). 


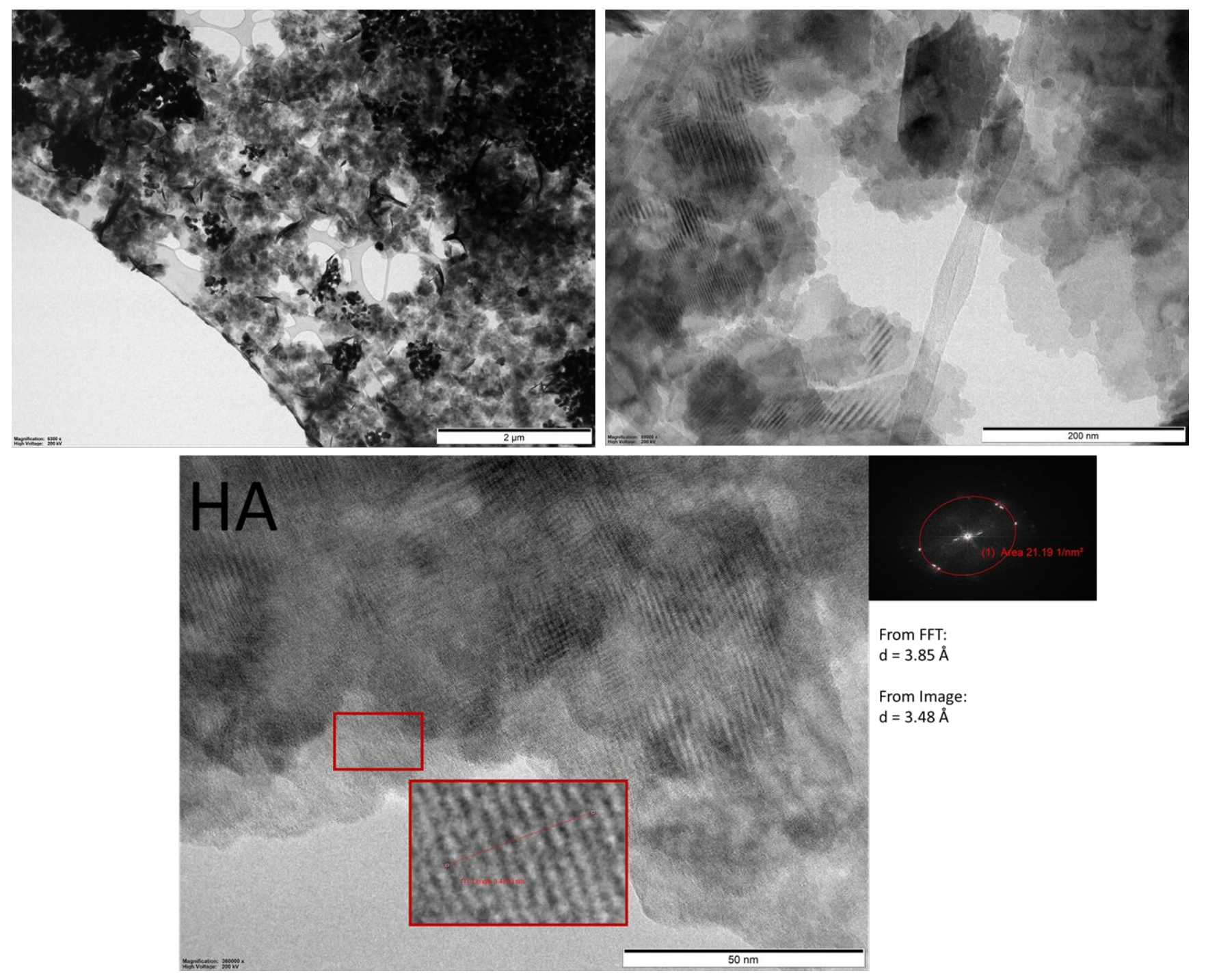

Figure S11. Representative HR-TEM images of hydrothermally synthesized (HA) ${ }_{4} \mathrm{AgBiBr}_{8}$ with details on repetitive structures and associated distance (calculated both manually and through FFT). 

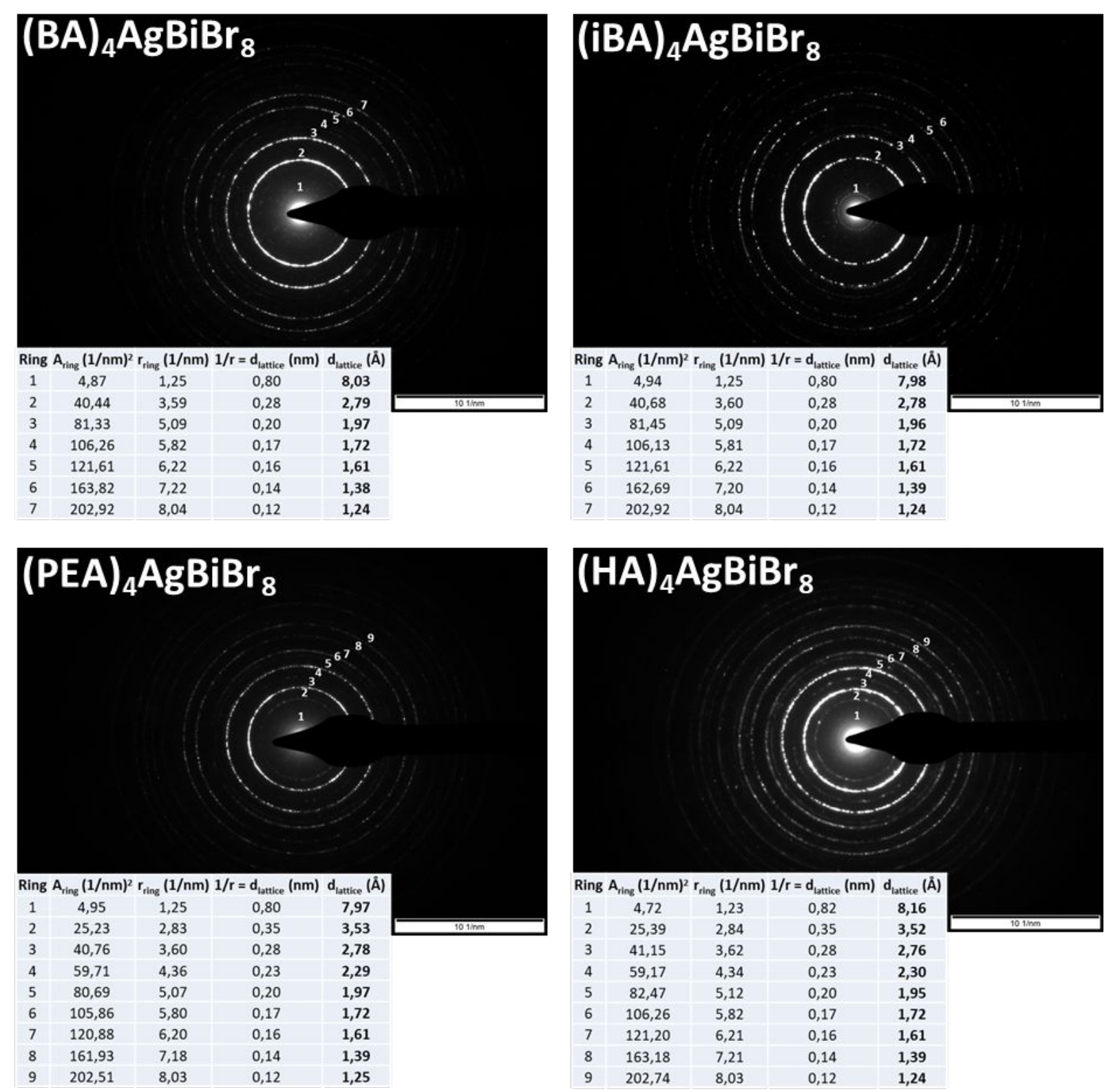

Figure S12. SAED patterns of the four hydrothermally synthesized (XA) ${ }_{4} \mathrm{AgBiBr}{ }_{8}$ with relative average lattice parameters. 


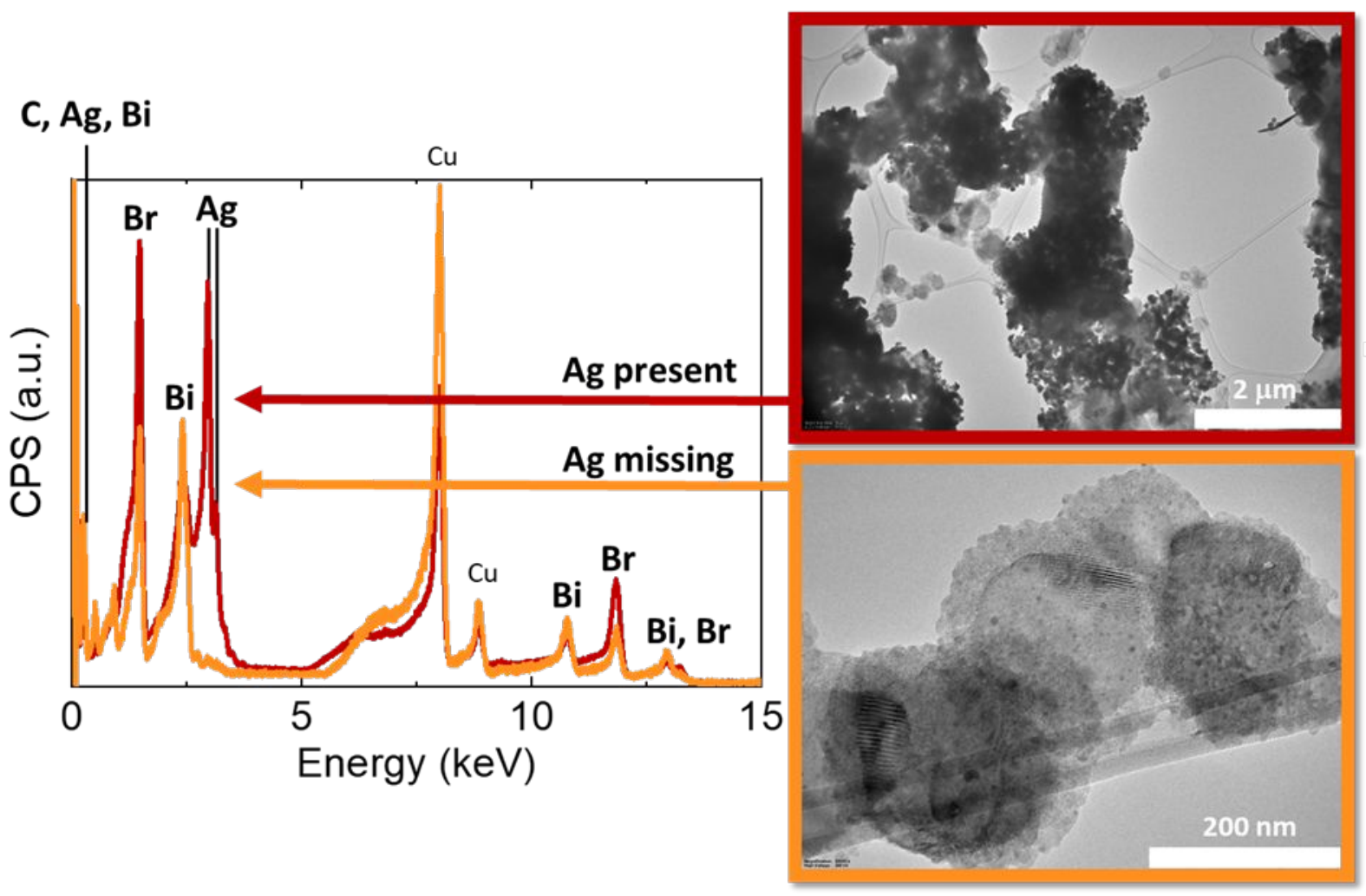

Figure S13. TEM EDX analysis of the hydrothermally synthesized $(\mathrm{BA})_{4} \mathrm{AgBiBr}_{8}$ crystalline sample, showing the existence of two different regions characterized by the presence and absence of $\mathrm{Ag}$ atoms (the $\mathrm{Cu}$ signal stems from the TEM grid). 


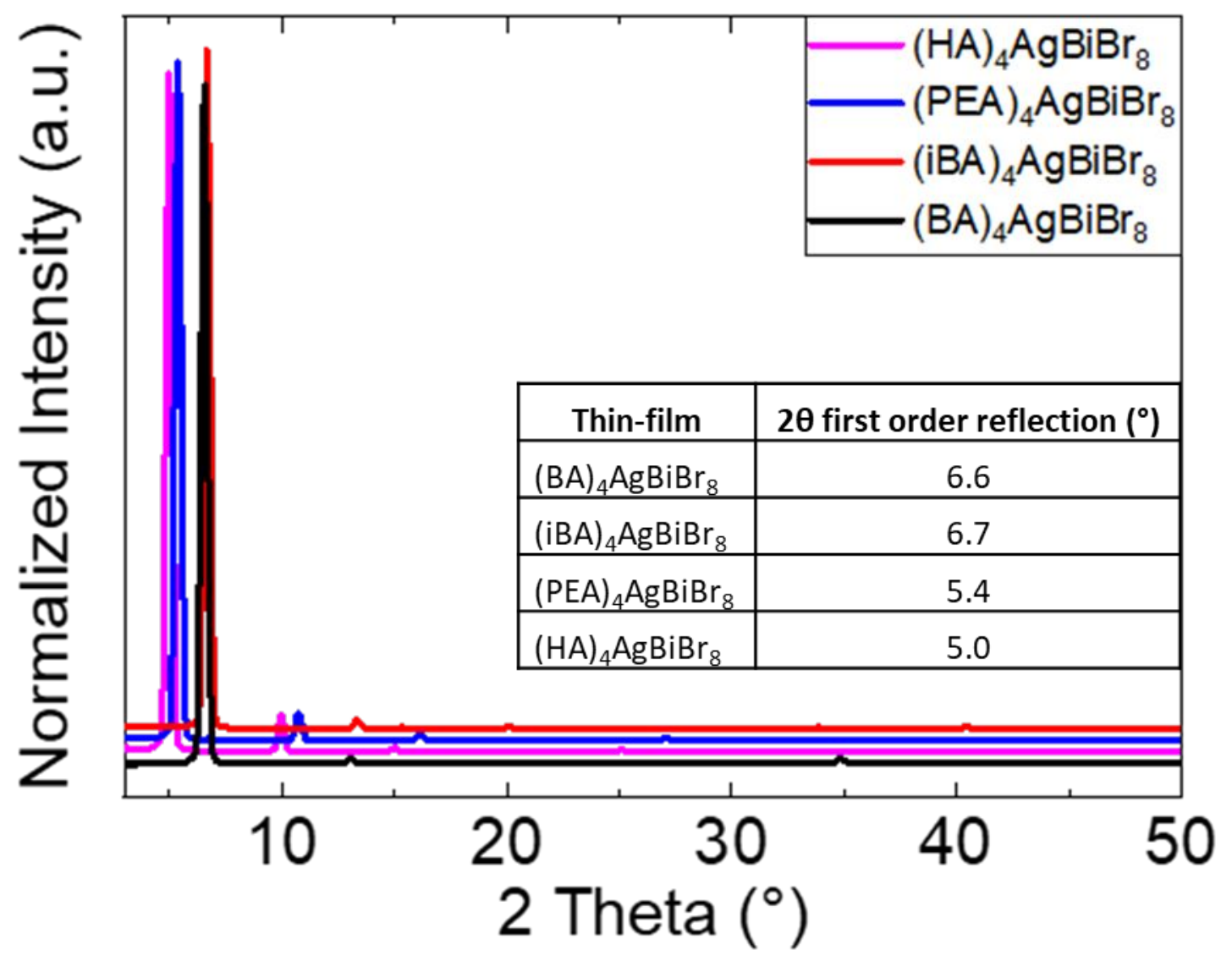

Figure S14. Thin film XRD patterns of spin-coated thin films of the four (XA) $)_{4} \mathrm{AgBiBr}_{8} 2 \mathrm{D}$ monolayers double perovskites. The inset table reports the exact value of the maximum in the first order (001) reflections. The average crystallite size for the four thin films, calculated by applying the Scherrer equation to the first order reflection, results to be $24.4 \pm 0.3 \mathrm{~nm}$.

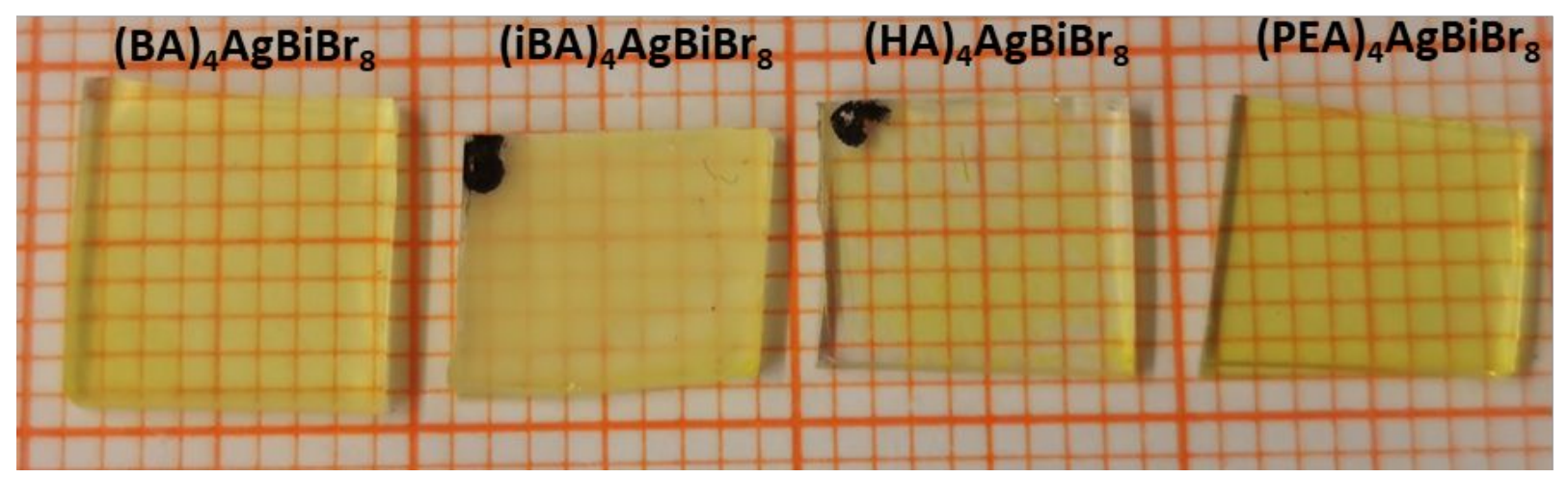

Figure S15. Photos of the thin films obtained from the four (XA) $)_{4} \mathrm{AgBiBr}_{8} 2 \mathrm{D}$ monolayers double perovskites on glass slides that show their visual appearance. 

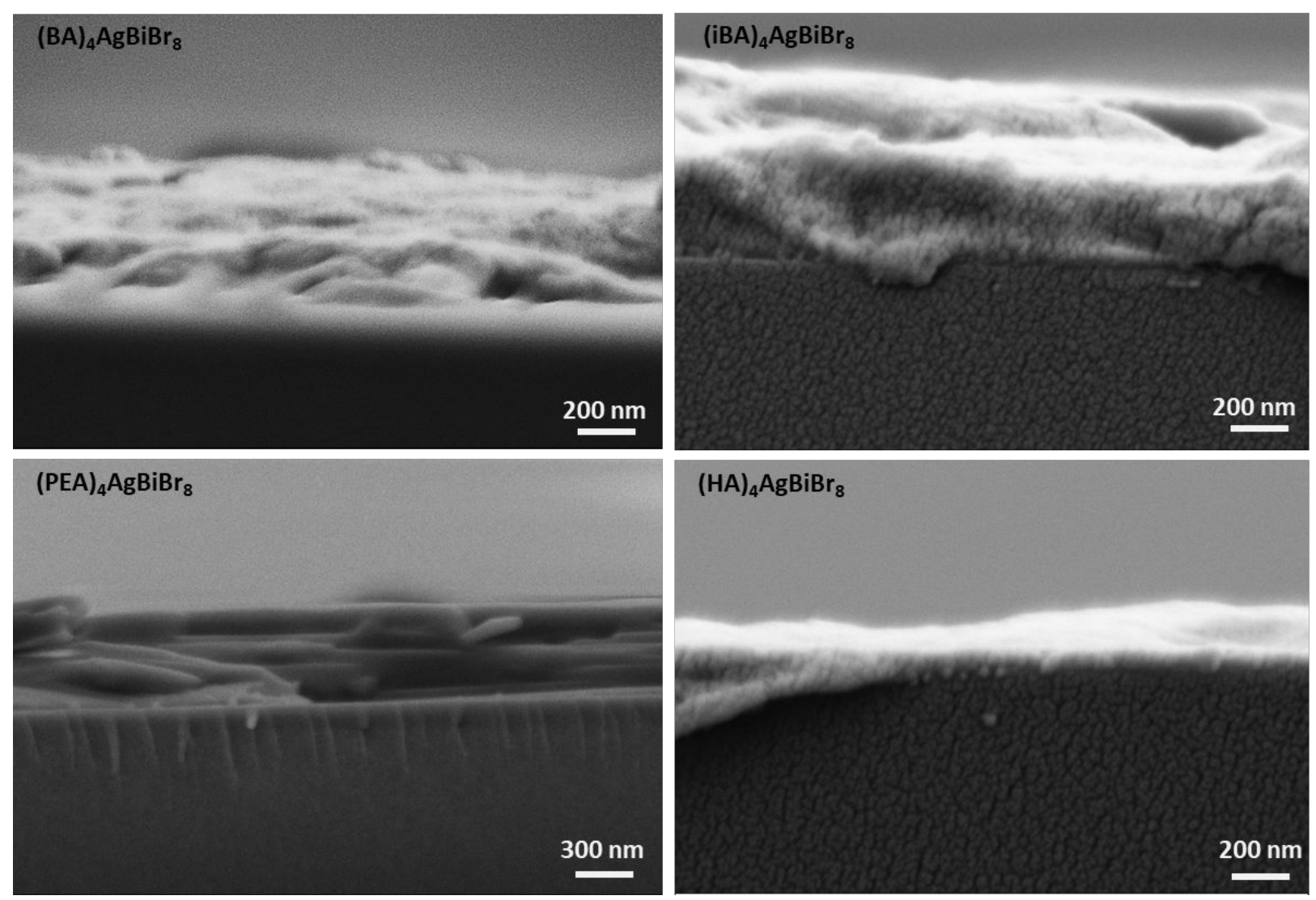

Figure S16. Cross-section SEM images of spin-coated thin films of the four (XA) ${ }_{4} \mathrm{AgBiBr}_{8} 2 \mathrm{D}$ monolayers double perovskites. 

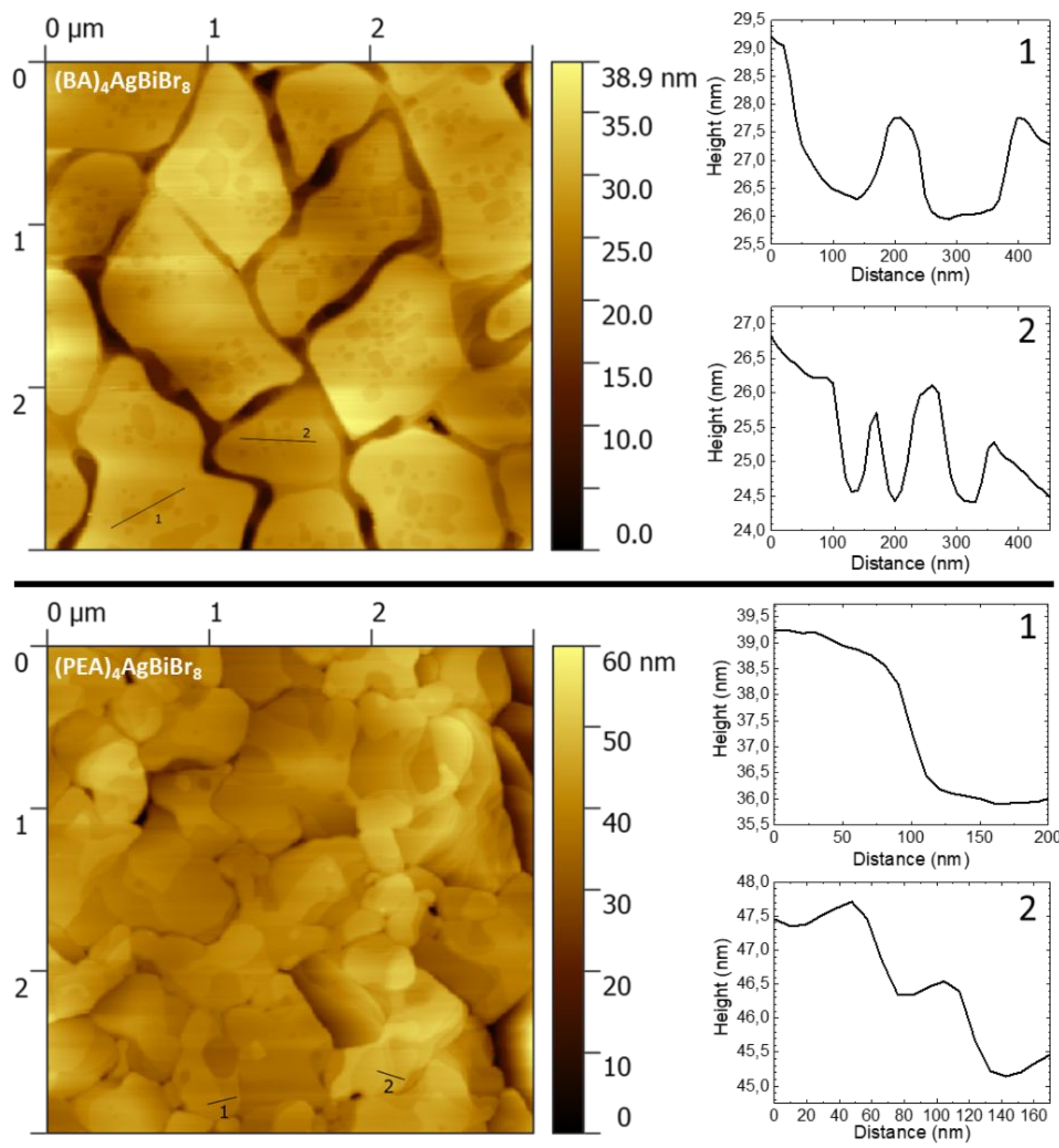

Figure S17. AFM topography images of spin coated thin films of (BA) ${ }_{4} \mathrm{AgBiBr}_{8}$ (top) and $(\mathrm{PEA})_{4} \mathrm{AgBiBr}_{8}$ (bottom) with representative cross-section height profiles. 


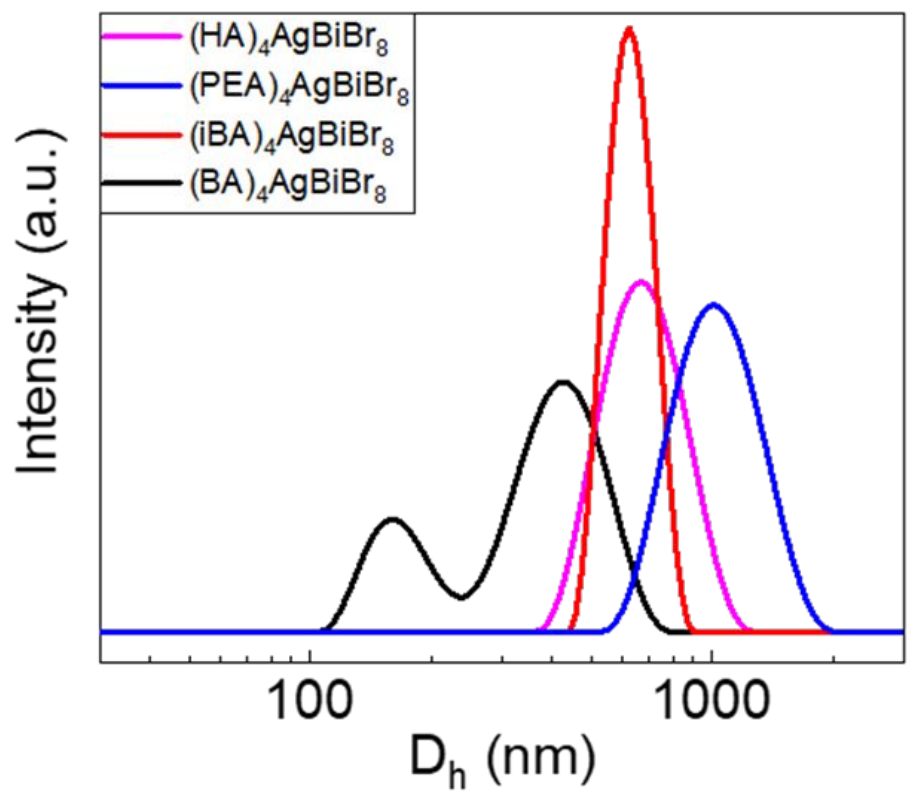

Figure S18. DLS size distributions of the DMF solutions used for processing the four $(\mathrm{XA})_{4} \mathrm{AgBiBr}_{8} 2 \mathrm{D}$ monolayers double perovskites into thin films. 

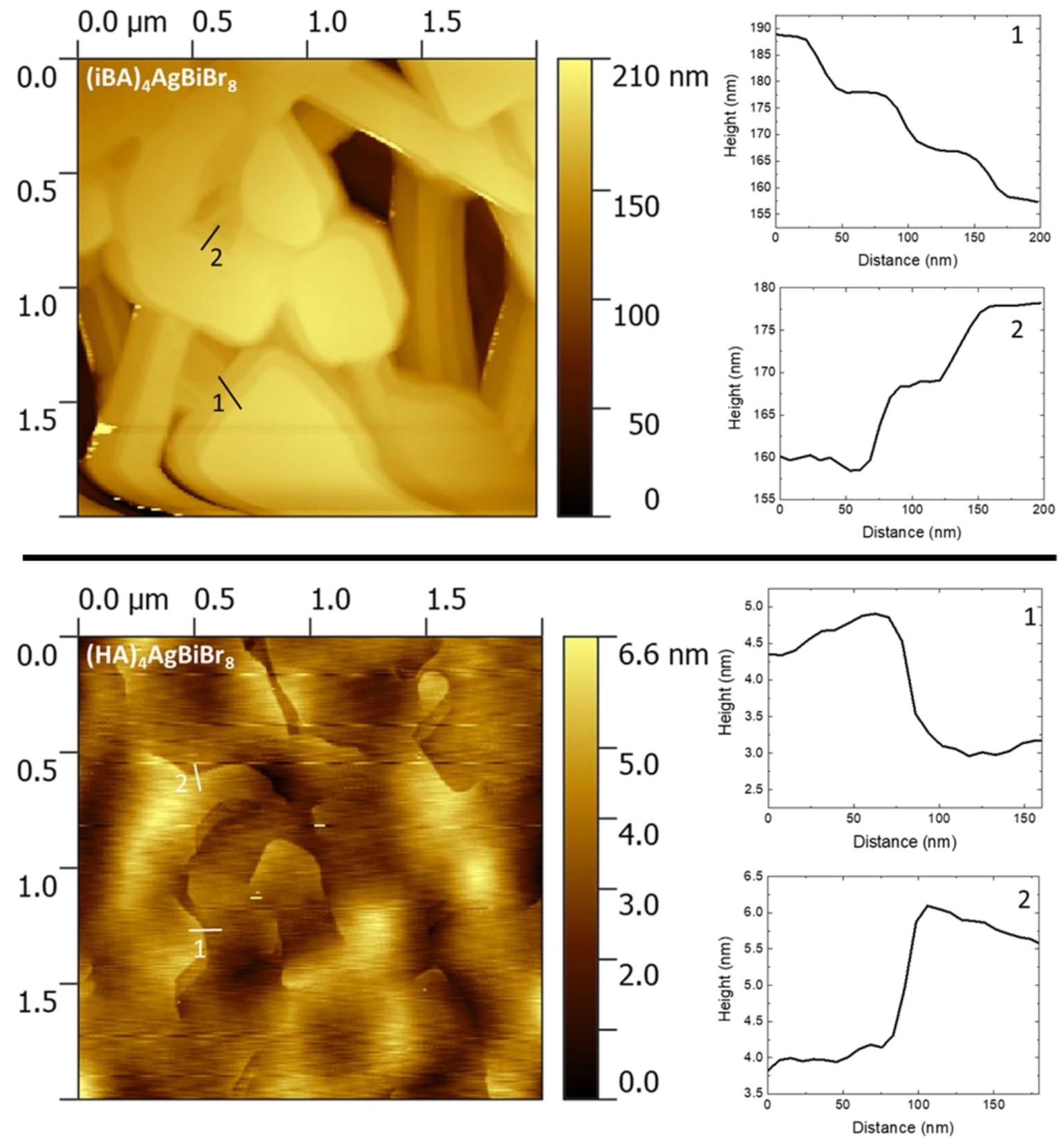

Figure S19. AFM topography images of spin coated thin films of (iBA)4AgBiBr8 (top) and (HA) $4 \mathrm{AgBiBr} 8$ (bottom) with representative cross-section height profiles. 
a)

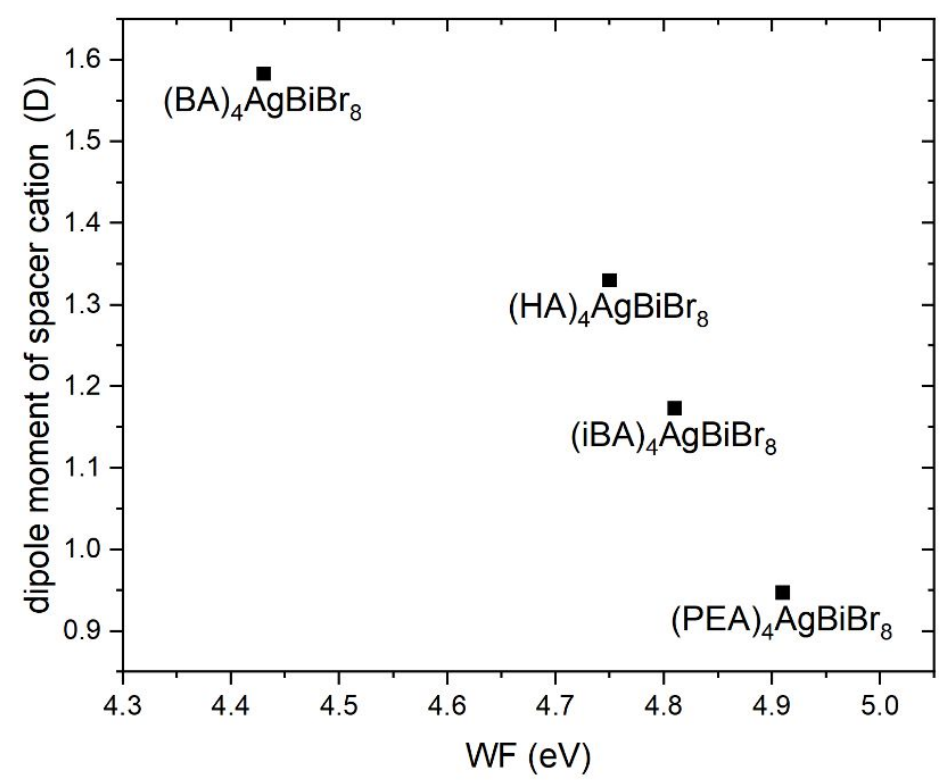

b)
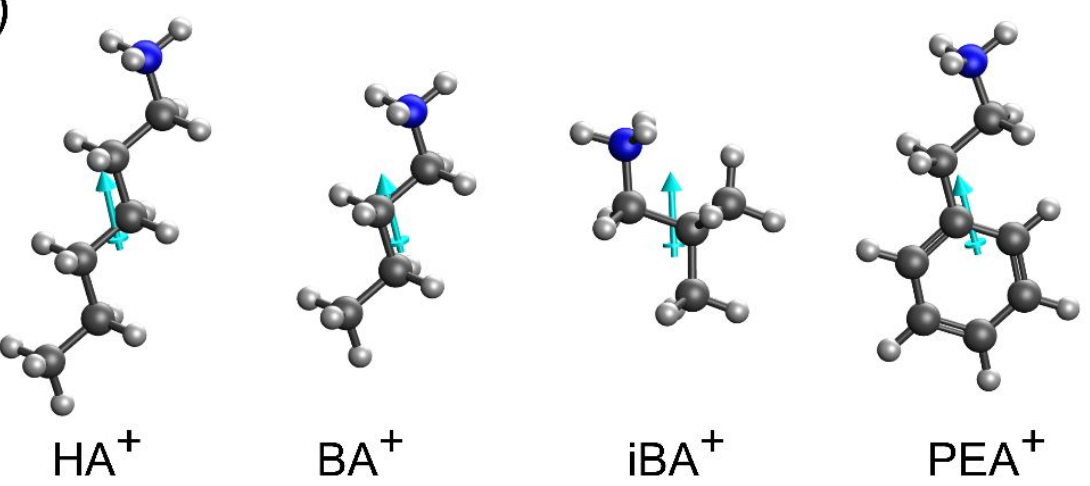

Figure S20. a) WF of (RA) ${ }_{4} \mathrm{AgBiBr}$ as a function of the calculated dipole moment of the organic cations $\mathrm{RA}^{+}$shown in $\left.\mathrm{b}\right)$. 


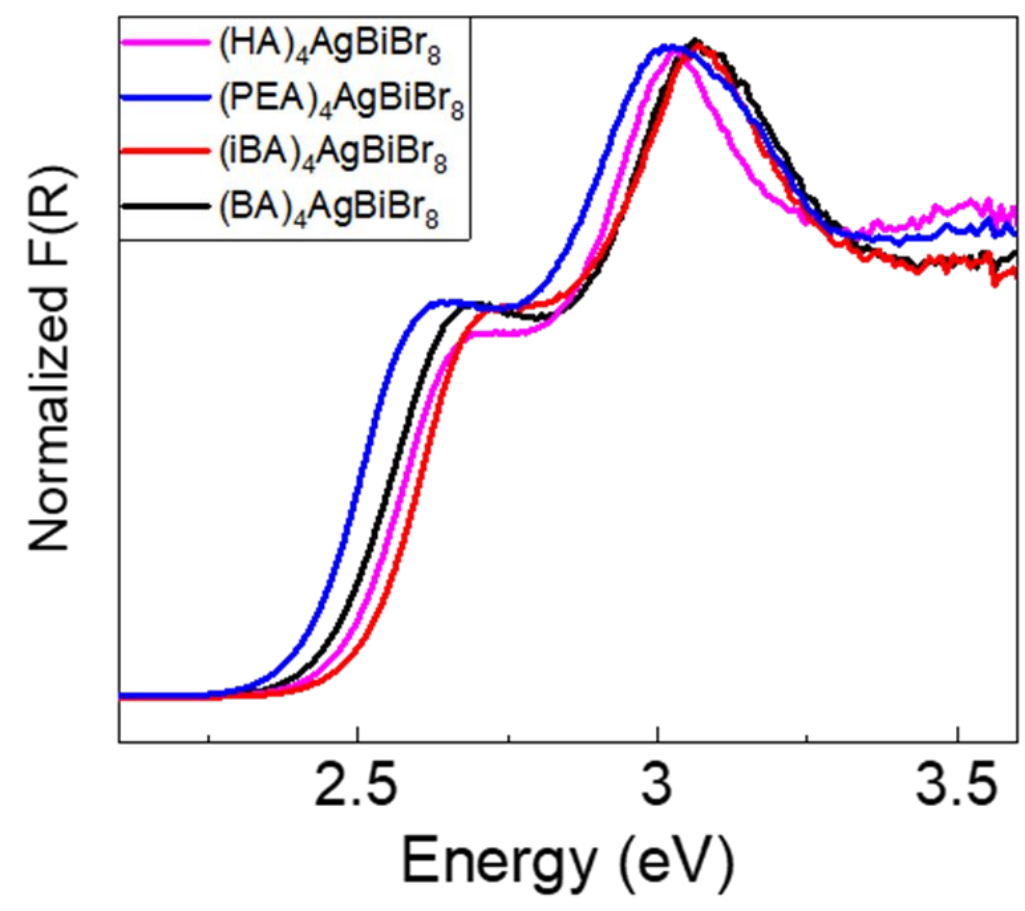

Figure S21. Normalized diffuse reflectance spectra (Kubelka - Munk function vs. energy) of the four hydrothermally synthesized ( $\mathrm{RA})_{4} \mathrm{AgBiBr}_{8} 2 \mathrm{D}$ monolayers double perovskites crystalline powders. 


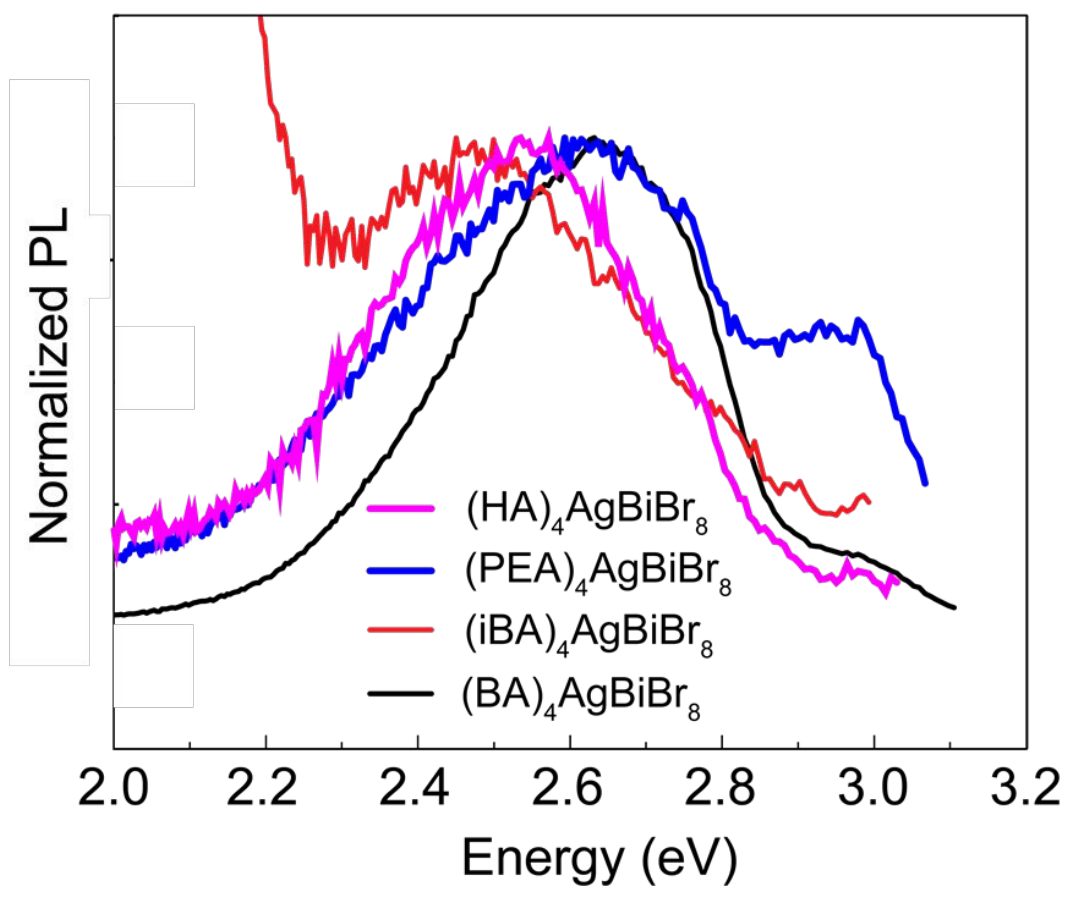

Figure S22. Normalized PL spectra of the four (RA) $)_{4} \mathrm{AgBiBr}_{8} 2 \mathrm{D}$ monolayers double perovskites thin films.
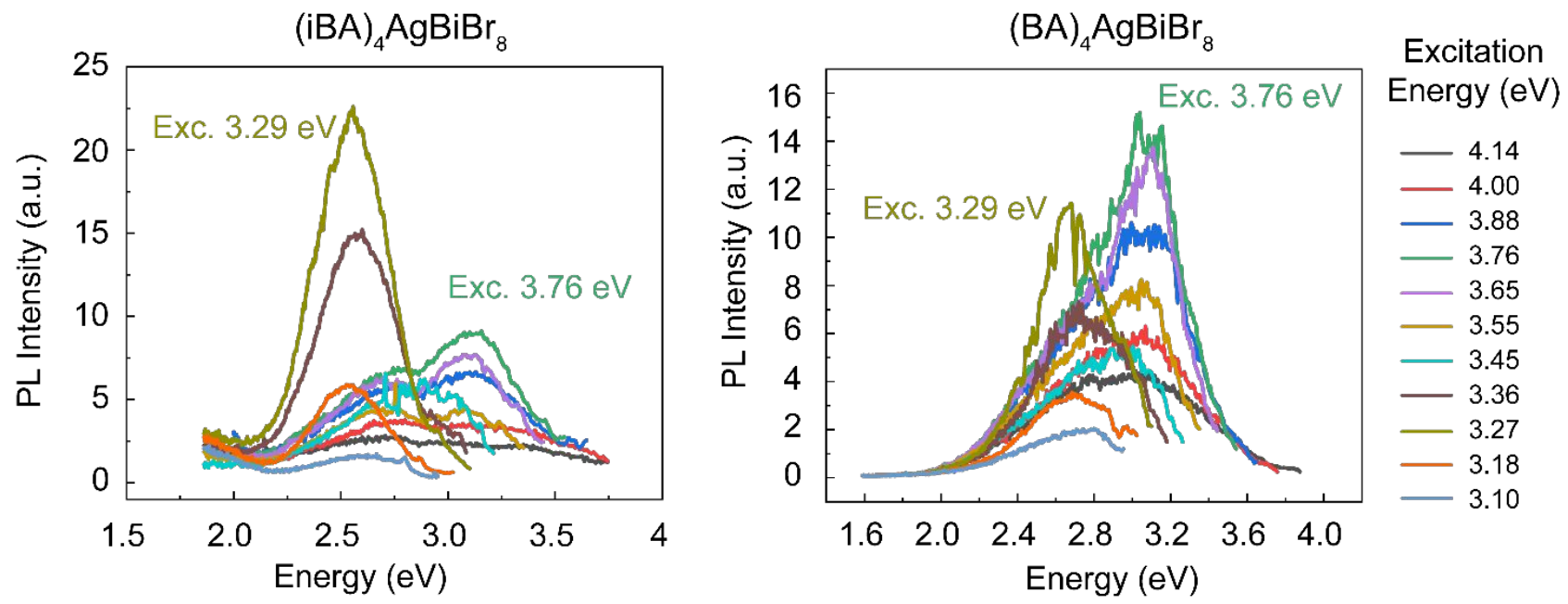

Figure S23. PL spectra of the (iBA) ${ }_{4} \mathrm{AgBiBr}_{8}$ and $(\mathrm{BA})_{4} \mathrm{AgBiBr}_{8}$ hydrothermally synthesized 2D monolayer double perovskites crystalline powders 
Table S2. Integrated PL values for the $(\mathrm{RA})_{4} \mathrm{AgBiBr}_{8}$ series under $3.29 \mathrm{eV}$ excitation

\begin{tabular}{|l|c|c|}
\hline \multicolumn{1}{|c|}{ Compound } & $\begin{array}{c}\text { Integrated PL } \\
\text { (a.u.) }\end{array}$ & $\begin{array}{c}\text { Comparison } \\
\text { with iBA }\end{array}$ \\
\hline$(\mathrm{BA})_{4} \mathrm{AgBiBr}_{8}$ & $1.4 \times 10^{10}$ & 0.65 \\
\hline$(\mathrm{iBA})_{4} \mathrm{AgBiBr}_{8}$ & $2.2 \times 10^{10}$ & - \\
\hline$(\mathrm{PEA})_{4} \mathrm{AgBiBr}_{8}$ & $3 \times 10^{9}$ & 0.13 \\
\hline$(\mathrm{HA})_{4} \mathrm{AgBiBr}_{8}$ & $8 \times 10^{9}$ & 0.37 \\
\hline
\end{tabular}

Table S3. Energy gaps vs computational setup in $\mathrm{G}_{0} \mathrm{~W}_{0}$ calculations of $(\mathrm{BA})_{4} \mathrm{AgBiBr}_{8}$. The k-grid in the $\mathrm{BZ}$ was reduced to $2 \times 2 \times 1$ in order to perform the tests. Based on results in the Table the following computational setup has been set in $\mathrm{G}_{0} \mathrm{~W}_{0}$ calculations: $\mathrm{k}$-grid $4 \times 4 \times 1$, EXX cutoff $30 \mathrm{Ry}$, dielectric matrix cutoff $3 \mathrm{Ry}$, total number of bands in dielectric matrix and correlation energy has been further increased to 2560 .

\begin{tabular}{|c|c|}
\hline Computational setup & $\mathbf{E}_{\mathbf{g}}(\mathbf{e V})$ \\
\hline Exchange cutoff $v$ S HF gap & 7.72 \\
20 Ry & 8.21 \\
40 Ry & 8.20 \\
\hline Dielectric matrix cutoff $v$ s band gap & \\
(fixed EXX cutoff=20 Ry; total number of bands 512) & \\
1 Ry & 4.48 \\
2 Ry & 4.38 \\
3 Ry & 4.35 \\
\hline Total number of bands $v$ band gap & \\
(fixed EXX cutoff =20 Ry; Dielectric matrix cutoff =1 Ry) & 4.48 \\
512 & 3.51 \\
1024 & 3.33 \\
1536 & 3.27 \\
\hline 2048 & \\
\hline
\end{tabular}




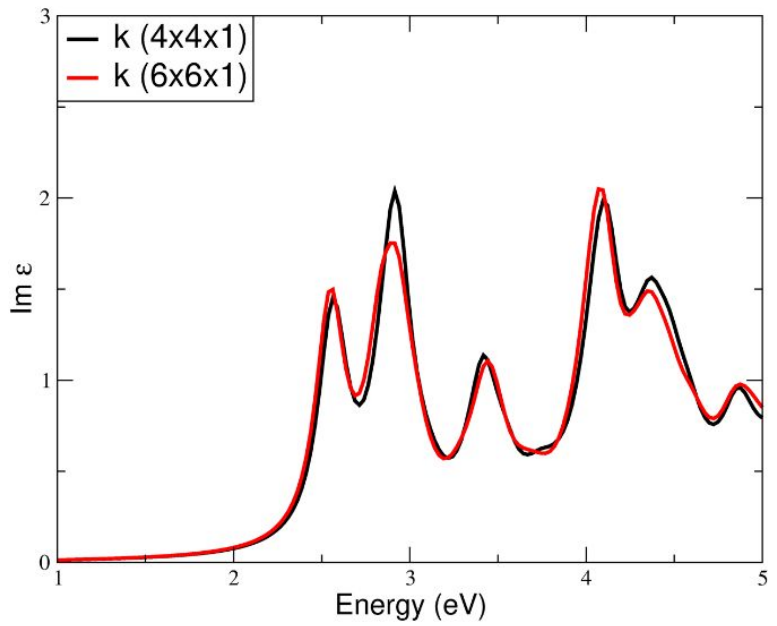

Figure S24. BSE spectra of $(\mathrm{BA})_{4} \mathrm{AgBiBr}_{8}$ calculated for two different k-point grids, i.e. $4 \times 4 \times 1$ and 6x6x1, and by using the scissor operator $(1.56 \mathrm{eV})$. Computational parameters: BSE exchange (screening) cutoff of 30 Ry (3 Ry), 20 occupied / 20 unoccupied bands; screening: exchange (dielectric matrix) cutoff of 30 Ry (3 Ry), 2560 total bands. 